\title{
Lunar Resource Utilization: Development of a Reactor for Volatile Extraction from Regolith
}

\author{
Julie E. Kleinhenz ${ }^{*}$ \\ Case Western Reserve University, Cleveland, $\mathrm{OH} 44106$ \\ Kurt R. Sacksteder ${ }^{\dagger}$ \\ NASA Glenn Research Center, Cleveland, OH 44135 \\ and \\ Vedha Nayagam ${ }^{\ddagger}$ \\ National Center for Space Exploration Research, Cleveland, OH 44135
}

\begin{abstract}
The extraction and processing of planetary resources into useful products, known as InSitu Resource Utilization (ISRU), will have a profound impact on the future of planetary exploration. One such effort is the RESOLVE (Regolith and Environment Science, Oxygen and Lunar Volatiles Extraction) Project, which aims to extract and quantify these resources. As part of the first Engineering Breadboard Unit, the Regolith Volatiles Characterization (RVC) reactor was designed and built at the NASA Glenn Research Center. By heating and agitating the lunar regolith, loosely bound volatiles, such as hydrogen and water, are released and stored in the reactor for later analysis and collection. Intended for operation on a robotic rover, the reactor features a lightweight, compact design, easy loading and unloading of the regolith, and uniform heating of the regolith by means of vibrofluidization. The reactor performance was demonstrated using regolith simulant, JSC1, with favorable results.
\end{abstract}

\section{Introduction}

$\mathrm{T}$ HE extraction and processing of planetary resources into useful products will have a profound impact on the future of space exploration of the moon and Mars. Known as In-Situ Resource Utilization (ISRU), this idea of "living off the land" reduces dependence on Earth for mission consumables such as propellant, and life-support oxygen and water. This enables safer, cheaper and longer duration mission scenarios.

A significant fraction of the lunar regolith is chemically-bound oxygen; and volatile species such as hydrogen (and possibly water at the lunar poles) are present in smaller concentrations. The goal of the RESOLVE (Regolith and Environment Science, Oxygen and Lunar Volatiles Extraction) project is to quantify these resources and demonstrate how to extract them.

\section{The RESOLVE Project}

Intended as a package concept for a lunar robotic lander mission, the RESOLVE project encompasses collection and processing of $\sim 400 \mathrm{~g}$ regolith samples. The system includes; extraction of soil samples using a coring drill, characterization of bulk regolith properties and mineralogical content, evolution of volatiles in a reactor, detection of evolved gases using a gas chromatograph, and capture and re-release of the volatiles using absorbent

\footnotetext{
* Research Associate, Department of Mechanical and Aerospace Engineering, Mail to: NASA Glenn Research Center, MS 77-5, 21000 Brookpark Rd. Cleveland, OH, 44135, non-member

${ }^{\dagger}$ Senior Combustion Scientist, Space Processes and Experiments Division, NASA Glenn Research Center, MS 77-5, 21000 Brookpark Rd. Cleveland, OH, 44135, Associate Fellow

₹ Senior Scientist, National Center for Space Exploration Research, Cleveland, MS 110-3, 21000 Brookpark Rd. Cleveland, OH, 44135, non-member
} 
beds. The objective of the package is to demonstrate the feasibility of ISRU related tasks, especially volatile and oxygen extraction processes. The results of this work will be used in the design of larger-scale processing plants that would be implemented as part of a lunar outpost.

The extraction process encompasses two modes of operation; the Regolith Volatiles Characterization (RVC) and Regolith Oxygen Extraction (ROE). The RVC process targets loosely bound volatiles such hydrogen or water (from ice). These volatiles are evolved by heating the regolith. Simply agitating the soil may also release some loosely bound solar wind gases. The ROE process extracts oxygen using hydrogen reduction of iron oxides contained in regolith. This process requires operating temperatures approaching $1000^{\circ} \mathrm{C}$. Separate reactors were built so that the different processes could be examined in detail. Future iterations of the project will combine the functions into one reactor. This paper describes only the RVC reactor.

\section{A. Lunar environment challenges}

The lunar environment presents several unique challenges to the system design. At the lunar poles, where ice may exist in the soil, the ambient temperature can be $-230^{\circ} \mathrm{C}$. The lunar ambient pressure is $\sim 1 \times 10^{-8} \mathrm{~Pa}$, and the gravity level is $1 / 6^{\text {th }}$ of normal earth gravity. These environmental factors may heavily influence both instrument behavior and design. The system must also cope with the abrasiveness of the lunar soil which affects hardware durability as well as ability to seal.

The approach is to deal with these challenges in a stepwise fashion. The first phase of this project (which is the scope of this report) primarily addresses the processing of the regolith, isolated from the lunar environment. The lunar temperature, pressure, and gravity issues, will be considered more thoroughly in subsequent iterations

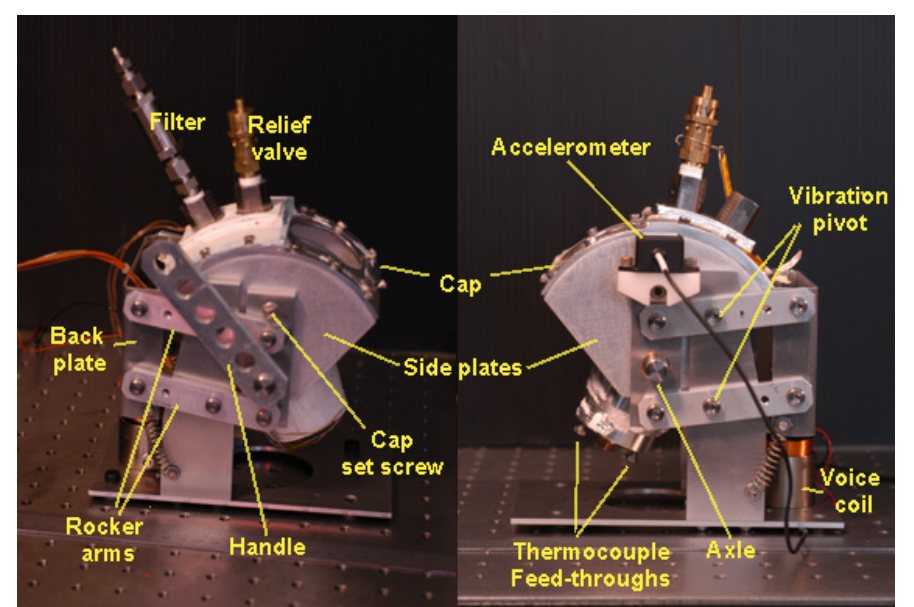

Figure 1. The RESOLVE RVC reactor. The images are from early assembly, so the insulation is not complete.

\section{The Regolith Volatiles Characterization (RVC) Reactor}

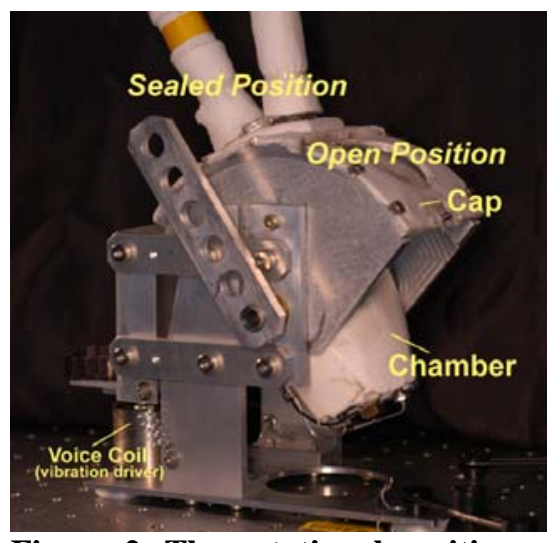

Figure 2. The rotational positions of the reactor. In this image, the chamber is in the sealed position. When rotated to the open position, the chamber lines up with a hole in the cap to allow loading of soil.
The RVC reactor, for the volatile extraction aspects of the project, was designed, built, and tested at the NASA Glenn Research Center. The 200cc aluminum reactor (Fig. 1) can hold approximately 100g of soil, filling up as much as half its volume. The chamber walls are heated, and water bound to the soil (e.g. in the form of ice) is released as steam. Other loosely-bound volatiles, such as hydrogen or nitrogen may also be released during heating. The pressure in the chamber increases as gases are generated, potentially reaching a maximum of $\sim 1 \mathrm{MPa}$ (150psia) at $150^{\circ} \mathrm{C}$. The evolved gases are then pressure fed to analysis modules elsewhere in the RESOLVE package.

The maximum operating temperature was selected based on the vapor pressure of the evolved water. At $150^{\circ} \mathrm{C}, 0.5 \mathrm{~g}$ of water can exist as saturated vapor in the reactor volume at a pressure of $\sim 0.5 \mathrm{MPa}$ (69psia). The maximum operating pressure was selected to accommodate this partial pressure of water, plus the other evolved volatiles. The target water detection value for RESOLVE was approximately $0.2 \mathrm{~g}$ of water, which is at the low end of the range predicted by Lunar Prospector (Ref. 1). Therefore, at $150^{\circ} \mathrm{C}$ saturated conditions should not occur in the reactor, avoiding the risk of condensation.

In order to accurately measure the evolved gases, the water must

\footnotetext{
* From RESOLVE project document by Taylor, J., Taylor, L., and Duke, M. entitled; “Concentrations of Volatiles in the Lunar Regolith.” 2006.
} 
remain in the vapor state at all times. Thorough heat tracing was required to prevent condensation in the system. Although a central embedded heater would have expedited soil heating, there would be more of a condensation risk on the walls. This was avoided by heating the soil via the chamber walls.

To process multiple batches of lunar soil, the reactor can be rotated to accept fresh soil and dispose of processed soil. Similar to a ball valve, the chamber rotates beneath a curved cap between the open (soil entry) and sealed (gas evolution) positions (Fig. 2). The chamber and cap assembly can then be rotated to drop the soil sample. This scheme could be easily automated for remote operations. It also features only one sealing surface, reducing the potential for leaks.

The heating process is expedited using vibrational mixing, which is a low-power, efficient means of improving heat transfer in lunar soil. Alternative mixing schemes, such as a mechanical stirrer inside the chamber, could clog and would not endure well in the abrasive lunar soil. Additionally, the vibration provides a means to 'shake loose' small soil particles that may otherwise bind or clog the system. The vibration of the reactor is induced by a small speaker coil coupled to the reactor through a mechanical linkage.

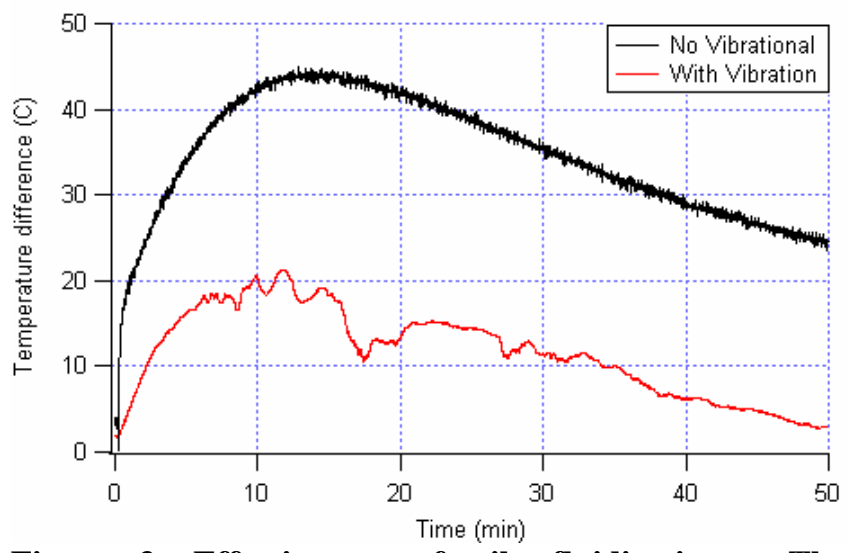

Figure 3. Effectiveness of vibrofluidization. The temperature difference between the heated wall and a thermocouple embedded in the soil at the center of the chamber is plotted versus time. The initial pressure of this test was room ambient.

\section{A. Vibrofluidization}

Vibrational mixing of the lunar soil simulant was characterized to find the optimal heat transfer mode. As indicated in earlier tests (Ref. 2,3), vibration effectiveness is characterized in terms of dimensionless acceleration, or g-level. As g-level increases, the circulation patterns within the bed change and become more vigorous. The frequency of vibration has a lesser influence, primarily shifting the g-level at which these patterns occur.

The acceleration was monitored using a single axis accelerometer mounted to the chamber. The frequency and amplitude could be adjusted independently to obtain the desired mixing. Unlike the transparent chamber used in Ref. 2, the circulation patterns could not be observed. Effectiveness of the mixing was gauged by the embedded thermocouples. Figure 3 shows the temperature difference between the heated chamber wall and the regolith in the center of the chamber. A nonfluidized case, where the heat transfer is purely conductive, is contrasted with vibrofluidized case. A lower temperature difference indicates a more effective heat transfer. The vibration in this case used a $60 \mathrm{~Hz}$ square wave at $\sim 3 g$ (RMS). This resulted in a maximum spatial variation in temperature of $20^{\circ} \mathrm{C}$ early in the heating process, decreasing to $5^{\circ} \mathrm{C}$ later.

The rotating 'ball valve' design required that the vibration be transferred to the chamber through lever arms. These linkages induced parasitic frequency modes attenuating the intended vibrations. The frequency modes can be seen in Fig. 4, which shows the results of the Fast Fourier Transform (FFT) of the acceleration

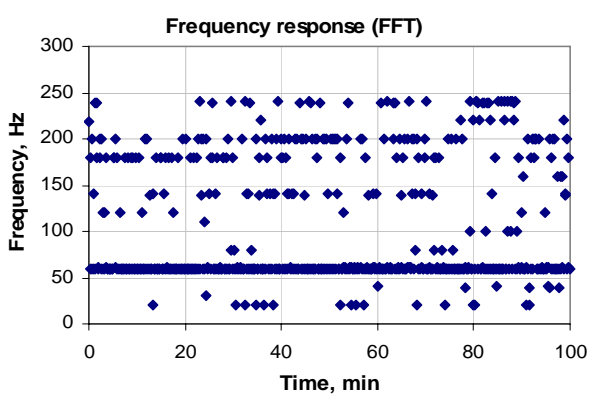

Figure 4. The Fast Fourier Transform (FFT) showing the frequency response of the vibration. The vibration was driven at $60 \mathrm{~Hz}$, but other frequency modes are evident.

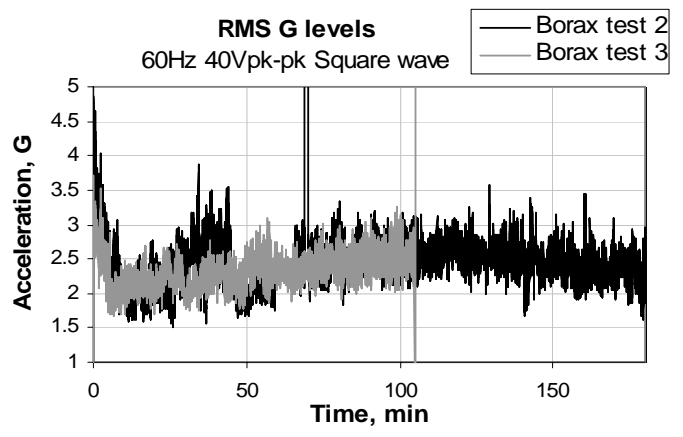

Figure 5. The acceleration trace from two tests with the same vibration settings. The fluctuation in the acceleration level due to the noisy frequency can be seen.

American Institute of Aeronautics and Astronautics 092407 
measurement. The vibration was driven at $60 \mathrm{~Hz}$, but response at other frequencies is evident. Figure 5 shows the acceleration values for two tests at the same vibration settings (test 2 corresponds with Fig. 4). The frequency noise also created variations in the acceleration. A driver directly on the chamber would be ideal and should be considered for future design.

\section{Experimental Results}

A series of engineering and scientific tests were performed to demonstrate the capabilities of this reactor before delivery to project partners at the Kennedy Space Center. Since actual lunar soil is in short supply, a soil 'simulant', known as JSC-1, was used.

\section{A. Heat Tracing}

The reactor was heat traced to provide a uniform temperature within the chamber. This included heating the chamber wall, as well as the cap, using resistively heated tape. The heat tape consisted of 2 parallel nichrome wires embedded in silicon adhesive. High temperature RTV was used to reinforce the adhesive and ensure good contact with the surface. The heated surfaces were then wrapped in Fiberfrax insulation (conductivity $0.19 \mathrm{~W} / \mathrm{mK}$ ) and heater controllers were used to maintain temperature. A maximum of $80 \mathrm{~W}$ ( $40 \mathrm{~W}$ for the chamber and $40 \mathrm{~W}$ for the cap) was used to reach $150^{\circ} \mathrm{C}$ in about one hour.

Thermocouple probes at various locations and infrared imaging indicated that uniform heating was achieved in the reactor. Liquid water was also added to the reactor (with no soil) and vaporized to test for cold (condensation) spots. The pressure increase was monitored during heating and the water was re-condensed in a dewar at the end of the test. If the pressure and collected water was less than predicted, then localized condensation would be an explanation. This method was also used to test the heat tracing of the fittings and lines.

\section{B. Condensation check}

Figure 6 shows the results of some of the liquid water tests used to check for condensation. The target temperature for the reactor and the amount of liquid water added is listed for each test. Pressure and chamber temperature are plotted versus time. The reactor reached $100^{\circ} \mathrm{C}$ in about 20minutes and $150^{\circ} \mathrm{C}$ in about 60 minutes. Since the chamber was not evacuated prior to the tests, the pressure rise is due to both water

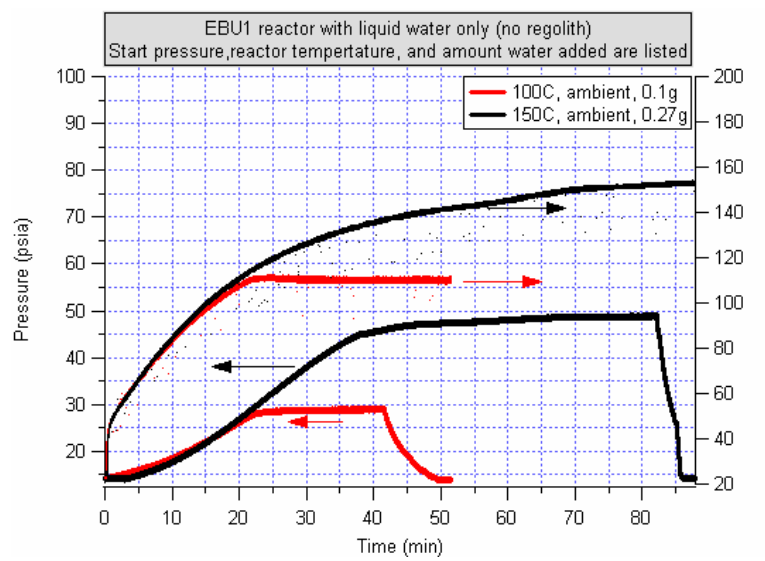

Figure 6. Tests to check for condensation in the reactor. Liquid water was added and the pressure monitored as it was vaporized. The pressure and temperature rise over time are plotted here.
Table 1: The end results from the tests shown in Figure 6. The expected pressure matched that test pressure, indicating that no condensation had occurred.

\begin{tabular}{|r|c|c|c|c|}
\hline $\begin{array}{l}\text { Water } \\
\text { added (g) }\end{array}$ & $\begin{array}{l}\text { Temperature } \\
(\mathrm{C})\end{array}$ & $\begin{array}{l}\text { Actual } \\
\text { Pressure } \\
\text { (psia) }\end{array}$ & $\begin{array}{l}\text { Expected } \\
\text { Pressure } \\
\text { (psia) }\end{array}$ & $\begin{array}{l}\text { Heated } \\
\text { atmospheric } \\
\text { gas (psia) }\end{array}$ \\
\hline 0.1064 & 100 & 29 & 29 & 18.4 \\
\hline 0.2657 & 150 & 48 & 49 & 20.5 \\
\hline
\end{tabular}

vaporization and the heating of atmospheric gases. Table 1 summarizes the results. The pressure results verify that no condensation occurred in the chamber.

\section{Water release with JSC1 and Borax}

To simulate an operational scenario, water evolution tests were done with the lunar soil simulant. Simply adding liquid water to the simulant would cause the soil to coalesce, preventing even distribution of water throughout the sample. Therefore water was added in the form of a hydrated mineral salt, borax. The grains of salt were well mixed with the soil, giving a more realistic representation of water that may be adsorbed onto lunar regolith. A thermogravimetric analysis (TGA) of borax performed by project partners at KSC indicated dehydration occurring at $\sim 90^{\circ} \mathrm{C}$. This approximates the 1atm boiling point of water, making it a good surrogate for ice or loosely bound water. 
The chemical formula for borax, $\mathrm{B}_{4} \mathrm{Na}_{2} \mathrm{O}_{7}+10 \mathrm{H}_{2} \mathrm{O}$, indicates that there are 10 moles of water for every mole of borax, such that borax is about $45 \%$ water by weight. The TGA showed full dehydration (45\% weight loss), but these tests were performed in a continuous nitrogen flow and a constant heating rate. In contrast the reactor is an isothermal stagnant environment of increasing humidity. Borax dehydration was therefore tested using a conventional kiln and in the reactor itself. The results of these tests would indicate the quantity of borax needed to give the desired water yield. Once integrated into the rest of the RESOLVE package, full scale tests could be done using these results.

Three tests were preformed with borax as part of the final hardware performance evaluation. The tests were performed sequentially and the soil was not unloaded between tests (to protect the seals). Instead, fresh hydrated borax was added to the simulant containing the dehydrated borax from previous tests. The chamber contained $100 \mathrm{ml}$ (172g) of JSC1 simulant, with $0.5 \mathrm{~g}$ of borax added in the first test. An additional $0.55 \mathrm{~g}$ of borax was added in the second test, and another $0.55 \mathrm{~g}$ in the third. Based on predictions from earlier tests, this amount of borax was expected to yield the desired $0.2 \mathrm{~g}$ of water. Water release was measured based on the pressure rise in the chamber. The final temperature of the soil in all tests was about $135^{\circ} \mathrm{C}$. Table 2 and Fig. 7 show the results. Notice that test three began with an elevated pressure, while

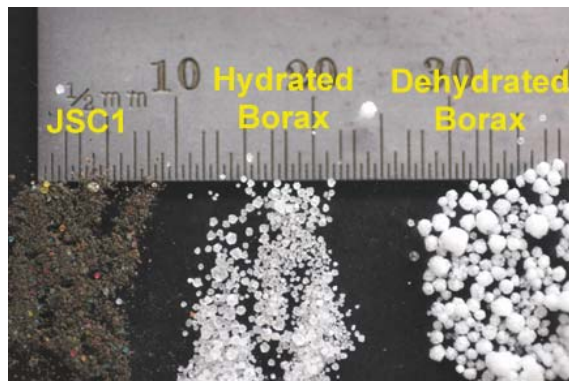

Figure 8. A comparison of the grain sizes of JSC1, hydrated borax, and dehydrated borax. The grain size of the borax increases when it dehydrates.
Table 2: The results from the tests with borax and JSC1. The amount of water released is indicated in terms of the borax mass loss. A fully dehydrated sample would result in a $45 \%$ loss. (the released water mass was calculated from the pressure rise).

\begin{tabular}{|l|c|c|c|c|c|}
\hline & $\begin{array}{l}\text { Borax } \\
\text { added } \\
\text { (g) }\end{array}$ & $\begin{array}{l}\text { Start } \\
\text { Pressure } \\
\text { (psia) }\end{array}$ & $\begin{array}{l}\text { Final } \\
\text { Pressure } \\
\text { (psia) }\end{array}$ & $\begin{array}{l}\text { Final } \\
\text { temperature } \\
\text { regolith (C) }\end{array}$ & $\begin{array}{l}\text { mass } \\
\text { loss of } \\
\text { borax }\end{array}$ \\
\hline Test 1 & 0.5 & 16.5 & 42.8 & 136 & 19 \\
\hline Test 2 & 0.55 & 14.9 & 37.8 & 136 & $16^{*}$ \\
\hline Test 3 & 0.55 & 83 & 123.4 & 133 & 8 \\
\hline
\end{tabular}

* One of the heater connections was temporarily lost causing a pressure drop.

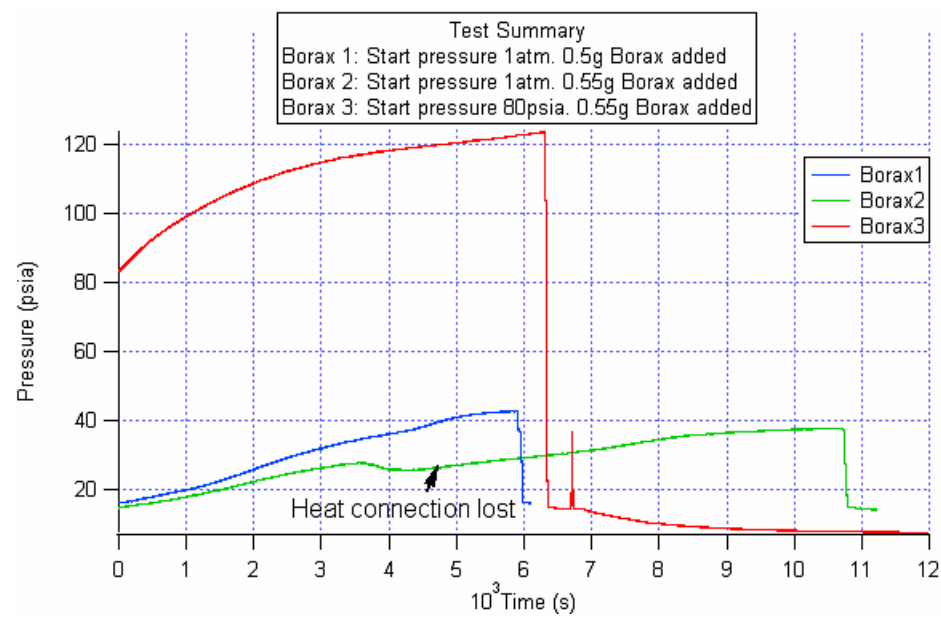

Figure 7. Pressure rise as water was released from the borax. Borax was mixed in with the JSC1 simulant. The plots correspond to the data in Table 2. the others began with atmospheric. This was done to simulate the release of other loosely bound volatiles that may be released along with water vaporization. The water release was much lower in this test indicating that dehydration may have a pressure dependence. Differences in heating times may also account for some variability in the results.

There was initial concern that as water vapor was generated, the simulant would be affected by the humid reactor environment, potentially affecting the fluidizing or heat transfer. Tests indicated that so long as no water condensed in the reactor, the fluidization was not affected (Fig. 5).

One interesting result from these tests was that the heat transfer improved in each successive test. The borax expands when it dehydrates, as shown in Fig. 8. Since JSC1 has a very low conductivity, it is possible that the increased the void space between simulant grains, due to borax expansion, improved the overall heat transfer. 


\section{Conclusion}

As part of the phase one engineering breadboard unit, the RESOLVE volatile extraction reactor was developed at the NASA Glenn Research center. The reactor was designed to uniformly heat a 100g soil sample and accumulate the evolved gases. Testing of the reactor demonstrated uniform heating with no condensation of the evolved water vapor.

Vibrofluidization demonstrated good soil mixing, significantly improving the heat transfer of the regolith simulant. However, the use of lever arms to transfer the vibration from the voice coil to the chamber introduced frequency noise in the vibration and attenuated the acceleration. Subsequent design iterations should employ direct vibration of the chamber to increase the efficiency of the voice coil.

Successful gas evolution and recovery was demonstrated using borax and JSC1, where the borax simulated water that may be adsorbed to the actual lunar soil. The dehydration characteristics of borax were explored to determine yield quantities for performance tests of the integrated system. More thorough exploration may be warranted if borax is to be used more extensively.

\section{Acknowledgments}

The authors gratefully acknowledge the support of the NASA Exploration Technology Development Program and the underlying In-Situ Resource Utilization Project for the support of this work.

\section{References}

${ }^{1}$ Feldman, W. C. et al. (2001), Evidence for Water Ice Near the Lunar Poles, J. Geophys. Res., Planets 106, \#E10, 23232 23252.

${ }^{2}$ Nayagam, V and Sacksteder, K. “A Vibrofluidized Reactor for Resource Extraction from Lunar Regolith,” STAIF 2006, Albuquerque, New Mexico. 2006.

${ }^{3}$ Nayagam, V and Sacksteder, K.. “Resonant Heat Transfer in a Vibrofluidized Reactor with Lunar Regolith Simulant,” STAIF 2008, Albuquerque, New Mexico, 2008 (to be published)

${ }^{4}$ McKay, D.S., Carter, J.L, Boles W.W., Allen, C.C, and Allton, J.H. “JSC1: A New Lunar Soil Simulant.” Engineering, Construction, and Operations in Space IV, ASCE, 1994. pp. 857-866 